\title{
Erratum to: Use of signals and systems engineering to improve the safety of warfarin initiation
}

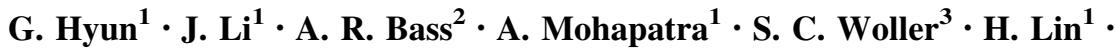 \\ C. $\mathrm{Eby}^{1}$ - G. A. McMillin ${ }^{4}$ B. F. Gage ${ }^{1}$
}

Published online: 24 August 2016

(C) Springer Science+Business Media New York 2016

\section{Erratum to: J Thromb Thrombolysis \\ DOI 10.1007/s11239-016-1402-z}

The original version of Appendix 2 unfortunately contained a typo in Eq. 3. The corrected equation for $\ln$ (dose estimate $)=$ $\ln ($ therapeutic dose). $[1-0.088$ (therapeutic INR - Target INR)].

Also, the authors wish to acknowledge the NIH for funding this research via R01 HL097036 and U54 HL112303.

The online version of the original article can be found under doi:10.1007/s11239-016-1402-z.
B. F. Gage
bgage@dom.wustl.edu
G. Hyun
hyung@slu.edu
J. Li
jli1@dom.wustl.edu
A. R. Bass
bassa@hss.edu
A. Mohapatra
amohapatra@wustl.edu
S. C. Woller
scott.woller@imail.org
H. Lin
hlin@dom.wustl.edu

C. Eby

eby@pathology.wustl.edu

G. A. McMillin

gwen.mcmillin@aruplab.com

1 Washington University School of Medicine, 660 S. Euclid Ave, Campus Box 8005, St. Louis, MO 63110, USA

2 Hospital for Special Surgery, Weill Cornell Medical College, 535 E 70th Street, New York, NY 10021, USA

3 Intermountain Medical Center, 5121 Cottonwood St, Murray, UT 84157, USA

4 Department of Pathology and ARUP Laboratories, University of Utah, 500 Chipeta Way, Salt Lake City, UT 84108, USA 